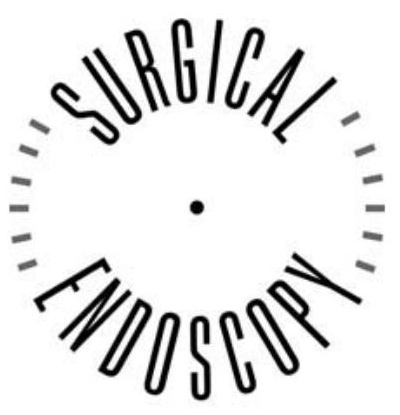

and Other Interventional Techniques

The full text versions of the abstracts presented here have been published online and are available for viewing at http://link.springer.ny.com. As a subscriber to Surgical Endoscopy, you have access to our LINK electronic service, including Online First.

\section{Laparoscopic excision of a Brunner's gland hamartoma of the duodenum}
H. G. Baladas, ${ }^{1,2}$ T. J. Borody, ${ }^{5}$ G. S. Smith, ${ }^{2}$
M. B. Dempsey, ${ }^{4}$ M. A. Richardson, ${ }^{2}$ G. L. Falk ${ }^{2,5}$
${ }^{1}$ Department of Surgery, 001165 Alexandra Hospital,
4735222 Singapore
${ }^{2}$ Department of Upper GI Surgery, Concord Hospital, Hospital
Road, Concord, Sydney, Australia 2139
${ }^{3}$ Department of Upper GI Surgery and Head Endosurgery, Concord
Hospital, Hospital Road, Concord, Sydney, Australia 2139
${ }^{4}$ Department of Surgery, Strathfield Private Hospital, Strathfield,
NSW 2135, Australia
${ }^{5}$ Department of Gastroenterology, Centre for Digestive Diseases, 144 Great North Road, Five Dock, Sydney, Australia 2046
Received: 16 April 2002/Accepted in final form: 2 May 2002/Online publication: 29 August 2002
DOI: $10.1007 / \mathrm{s} 004640040019$

Abstract. Brunner's gland hamartoma (adenoma) was first described in 1876. It is a rare hamartomatous lesion, with only $\sim 100$ cases reported in the world literature. Treatment has been by endoscopic snaring. Open surgical excision was reserved for cases where snaring had failed. We report a case of a Brunner's gland hamartoma $(2.4 \mathrm{~cm})$ that was successfully resected by laparoscopic techniques. Postoperative hospital stay was brief ( 2 days), and there were no complications. This is the second reported case to be resected laparoscopically.

Key words: Brunner's gland hamartoma - Duodenum - Adenoma - Hamartoma - Laparoscopic excision Correspondence to: G. L. Falk

\section{Laparoscopic removal of retroperitoneal accessory spleen in patient with relapsing idiopathic thrombocytopenic purpura 30 years after classical splenectomy}
A. Budzynski, ${ }^{1}$ A. Bobrzyński, ${ }^{1}$ T. Sacha, ${ }^{2}$ A. Skotnicki ${ }^{2}$
${ }^{1}$ 2nd Department of General Surgery, Collegium Medicum of Jag- iellonian University, Krakow, Poland
${ }^{2}$ Department of Haematology, Collegium Medicum of Jagiellonian University, Krakow, Poland
Received: 21 March 2002/Accepted in final form: 15 April 2002/Online publication: 12 August 2002
DOI: $10.1007 / \mathrm{s} 00464-002-4222-5$

Abstract. The clinical success of therapeutic splenectomy for idiopathic thrombocytopenic purpura depends on the complete removal of all functional splenic tissue. Among reasons for poor response to splenectomy, failure to remove accessory spleens is mentioned. We present our experience with laparoscopic removal of accessory spleen from retroperitoneal space in a patient with relapse of ITP 30 years after classical splenectomy. A 45-year-old female patient underwent in 1972 classical splenectomy for ITP. Progressive decline in thrombocyte count was observed 7 years ago. Scintigraphy, CT, and ultrasound revealed residual splenic tissue. A laparoscopic approach was proposed. Four trocars placed along left costal margin were used. After dissection of all the adhesions behind the pancreatic tail deep in the retroperitoneal space a round structure $4 \mathrm{~cm}$ in diameter, macroscopically resembling splenic tissue, was found. The accessory spleen was removed intact. The patient recovered well; 2 months later steroids were discontinued while the thrombocyte level was $251 \times 10^{9} / \mathrm{L}$. Identification of accessory spleen seems to be major intraoperative problem. We believe that accessory spleen can be safely removed laparoscopically, avoiding a major open procedure, and a satisfactory postoperative result could be expected.

Key words: Accessory spleen — Laparoscopic splenectomy - Idiopathic thrombocytopenic purpura

Correspondence to: A. Budzynski

\section{Intestinal perforation in a parastomal hernia by a migrated plastic biliary stent}

\section{A case report}

\section{J. M. Levey}

Division of Gastrointestinal and Hepatobiliary Medicine, Worcester Medical Center/Fallon Clinic, University of Massachusetts Medical School, 20 Worcester Center, Boulevard, Worcester, MA 01608 Received: 19 February 2002/Accepted in final form: 21 March 2002/ Online publication: 27 June 2002

DOI: $10.1007 / \mathrm{s} 00464-002-4506-9$

Abstract. Organ perforation is a well-described complication of plastic biliary stent placement [1-10]. Most commonly, a stent will cause duodenal perforation while still in the area of the biliary system. This often occurs in the setting of a periampullary diverticulum. Less frequently, a perforation occurs as a result of stent migration into the distal lumenal gastrointestinal tract. These cases have involved a migrated stent impacting at the level of the ileum or a sigmoid colon diverticulum. A plastic biliary stent causing perforation inside an 